\title{
Forum
}

\section{Reforming Qualifications: the how, the why and the who}

\author{
Caroline Bristow \\ University of Cambridge, Cambridge, UK
}

Key words: assessment, GCSE, GCE, Ofqual, exams reform

Like all teachers, when I was in the classroom, I knew inside out the syllabus I was teaching and the papers which would assess it. I also, however, gave very little thought to how these things had come to be. I had a vague sense that the 'Exam Board' had created them and awarded my students their grades, but they were a black box, moving in mysterious ways. I gave even less thought to the Powers That Be above and beyond the boards and the impact they had on me and my students.

Then I worked at an examination board. I was one of two Subject Specialists for Classics at OCR, part of Cambridge Assessment, with responsibility for qualifications in Latin, Greek, Classical Civilisation and Ancient History. I joined in February 2015, in the middle of the major reform of every GCSE, AS and A Level qualification offered in UK schools. I learned very quickly that my long-held assumptions were often at best merely incorrect, but at their worst had been actively preventing me from understanding the design and implementation of the curriculum I taught and more importantly - how I might best influence it to the benefit of future students.

This article offers a retrospective account of these reform years. This is in part to help people understand the decisions that were made then, but it is also written with an eye to the future. Qualifications will be reformed again, and the more people who understand what goes into this process the greater the diversity of voices who will (hopefully) contribute, and the better equipped the whole community will be to support their implementation.

\section{quis custodiet ipsos custodes?}

The reforms begun under Michael Gove as Secretary of State for Education aimed to fundamentally reimagine how GCSEs, AS and A Levels functioned. GCSEs were deemed to be lacking in challenge and substance, so were given a new '9-1' grading system and content was increased in all subjects to create a 'knowledge-rich approach'. The 'English Baccalaureate' (EBacc) was also introduced with the intention of promoting subjects that Ministers felt people valued: 'YouGov polling shows that the public values English, Maths and the sciences above all other subjects and that they hold languages, History and Geography in high regard.' (Gibb, 2019). The EBacc also fed into the new Progress 8 and Attainment 8 accountability measures (DfE, 2020). AS and A

Author of correspondence: Caroline Bristow, E-mail: ceb218@cam.ac.uk

Cite this article: Bristow C (2021). Reforming Qualifications: the how, the why and the who. The Journal of Classics Teaching 22, 60-63. https://doi.org/10.1017/S205863102100009X
Levels were decoupled, creating a two-year A Level course. Unlike GCSEs, however, there was no intention of changing the standard of content. A Levels were considered to be pitched correctly; the Department for Education just wanted them taught and examined differently.

The reforms took years to achieve, with subjects falling into three initial phases of reform known as 'tranches' as decided by the Department for Education. Classical Languages were in Tranche 2, whilst Classical Civilisation and Ancient History were placed in Tranche 3.

GCSE Classical languages were in a very unusual position. The mandate for all subjects was that challenge and content must increase, but the Classics subject community had long been advocating a reduction in set text content to reflect the realities of available teaching time in most schools. Latin and Greek GCSE carried 'no prior knowledge' statements, which meant that it was assumed the entire course could be taught from scratch in the standard two years available for a KS4 course. The Cambridge School Classics Project, Eduqas, OCR and others undertook extensive research and argued forcefully that it simply was not possible to teach the previously mandated 130 lines of set text plus language competency in just two years. A reduction to 90 lines was suggested.

The Department for Education compromised on 110 lines of set text and removed the 'no prior knowledge' statement. This, they said, acknowledged that these GCSE courses could not be taught from scratch at KS4; they would need to build on knowledge gained lower down the school. The boards accepted this compromise, despite it not reflecting the reality of many classrooms, as there was a concern that further push back could lead to the amount being increased again. The 'no prior knowledge' statement was key in achieving any decrease in set text length, so its removal risked this decision being reconsidered.

Classical Civilisation and Ancient History faced their own existential trials at the level of the Department for Education. Tranche 3 subjects were investigated carefully to ensure they were suitable for study as GCSE and GCE qualifications. Important factors in this evaluation included how well the subjects were regarded by $\mathrm{HE}$, if they were sufficiently rigorous to merit the award of a GCSE or GCE, and whether they were clearly distinct from other similar subjects. It soon became clear that the Department was not convinced that Ancient History and Classical Civilisation met their criteria. The greatest concern was that the two overlapped, and were not really separate, distinct subjects in their 
own right. If the Department could not be convinced of the legitimacy of these subjects, no GCSE or GCE in them would be offered post reform.

We came close to losing one or both of Classical Civilisation and Ancient History during this period as documents flew backwards and forwards covered in comments from civil servants communicating the concerns of their Minister. Eventually definitions were agreed which gave each subject its own identity and made them distinct enough to allay the worries of the Department for Education. Ancient History was tied tightly to the assessment objectives and aims of Modern History, including the use of period and depth studies and scope for the study of any geographical location in the period $3000 \mathrm{BC}$ to $500 \mathrm{AD}$. Classical Civilisation, however, was characterised as the study of the literature, material culture and thought of the Classical (defined as 'Greco-Roman') world in the period $3000 \mathrm{BC}$ to $500 \mathrm{AD}$.

These definitions were laid down in the Subject Content documents. Every subject offered at GCSE or GCE has one of these. Historically they have been relatively high-level overviews of key content which the Department for Education wishes to mandate for study in all subjects. These are usually written with input from experts who are consulted by the Department and are legally binding. All specifications must meet every criterion laid down in these documents or they will not be 'accredited' (signed off by the regulator for teaching in schools).

The Subject Content documents for Ancient Languages at GCSE (DfE, 2018) and AS/A Level (DfE, 2017a) were relatively uncontroversial other than the disagreement regarding lines of set text, and so were not changed dramatically from those previously in force. Those for Classical Civilisation at GCSE (DfE, 2016c) and at AS / A Level (DfE, 2016e) and for Ancient History at GCSE (DfE, 2016f) and at AS / A Level (DfE, 2016d), however, were far more complex, as were many of those for subjects in Tranche 3 . These are lengthy documents with a great many criteria and stipulations, all of which were mandatory. There was a great deal of negotiation during the authoring of these documents and the boards were deeply involved, but where disagreement occurred the Department had the final say; national qualifications must reflect what the Department of Education deems to be the correct content and objectives for study.

The enforcement of the subject content documents and creation of 'subject level conditions' (essentially rules around how courses must be assessed and constructed - for example, those for Ancient Languages can be found at the Department for Education (2017b)) is the responsibility of the regulator Ofqual. Ofqual ensures year on year that exam boards award fair and valid grades, but they also 'accredit' the specifications that are taught and check that these are then implemented correctly by the boards. They also handle the consultation process whereby they invite all interested parties to comment on documents such as those discussed above; for an example of this, see the outcome of the consultation on Classical Civilisation and Ancient History (DfE, 2016b). If Ofqual does not feel a proposed specification meets all the mandatory requirements, it will be rejected and must be re-written in line with the feedback. All Classical subjects went through multiple rounds of submission and re-drafting before they were finally accredited. The sense of relief when they were signed off was palpable!

It is worth noting that once the specification (and accompanying assessment rationale) is accredited, it becomes a legally binding document. Exam papers cannot require material not on the specification; students cannot be penalised for covering only what is in the specification document. If you think that a paper asks for knowledge not listed in the specification, or the questions do not follow the format they should, then you should let the board know as a matter of urgency as this is a problem.

This also means that textbooks should not be treated as the 'real specification' or anything along these lines. Textbooks are commissioned by publishers and written by people independent of the boards. 'Endorsement' is a process by which the board checks the book and essentially deems it an acceptable resource for use with the stated course. I also looked after Religious Studies A Level and we had three endorsed textbooks all from different publishers! If the textbook and specification disagree, it is the specification which is correct. It has to be. It is the legally accredited summary of the course. Information in the textbook which is not in the specification does not have to be taught (although it is probably there because the author thinks it is useful). If you are ever unsure of what you should be teaching or what is expected of your students, then read the specification first, not the textbook.

\section{How do you solve a problem like specification design?}

The practical implications of the above are that whilst the boards have a great deal of freedom in how they design and assess a qualification, that freedom is not boundless. It is worth looking at some of the criteria from the subject content documents and highlighting how this impacted on the eventual specification design and content. The qualifications in Classical Civilisation were my particular focus, so many of the examples given are from these, but similar decisions occurred in all subjects.

If one can prove to Ofqual that a Subject Content point has been met - which requires Ofqual to agree with your rationale then how this works in practice is very much in the hands of the individual boards. This can be seen clearly in the two available Latin GCSEs. OCR and Eduqas worked from the same regulatory documents and yet the final specifications look very different. As did the OCR Classical Civilisation A Level and the (eventually withdrawn) AQA one. AQA had numerous compulsory papers and small components covering very different material to that proposed by OCR, including prescribed texts by Aristotle and Plato and compulsory Roman art. OCR chose to create a specification with only one compulsory topic (Virgil's Aeneid) plus one Homeric epic and just two more components which were each a single topic of substantial size.

One infamous inclusion at Subject Content level was the requirement at A Level for students of Classical Civilisation to 'make use of knowledge and understanding of relevant secondary scholars and academics in order to further develop their analysis and argument' (see page 8 of the Subject Content (DfE, 2016a)). When AQA developed their specification, they proposed students study the forewords to the Epic translations and answer a specific exam question on it. At OCR we opted to make it a minor element of one of the essay types across all components. Both approaches were deemed to have met the stated requirement despite being totally different.

There was great concern at a regulatory level to make sure that all options in the qualification were of 'comparable' scope and difficulty. The steer was to reduce optionality to prevent issues with comparability; if everyone has to study the same things then one knows that every GCSE, AS or A Level in Classical Civilisation that is awarded represents exactly the same amount of work and knowledge. All of us working at OCR were determined to preserve the wide-ranging nature of Classical Civilisation and the ability for teachers to choose components which suited their own and their 
Literature written in Latin: material studied per $20 \%$ of qualification must be at least the equivalent of:

\begin{tabular}{|c|c|c|c|c|c|c|}
\hline $\begin{array}{c}\text { Epic } \\
\text { AS: } \mathbf{3 2 0 0} \text { lines } \\
\text { A: } 8000 \text { lines }\end{array}$ & $\begin{array}{l}\text { Extended verse } \\
\text { AS: } 800 \text { lines } \\
\text { A: } 2000 \text { lines }\end{array}$ & $\begin{array}{c}\text { Drama } \\
\text { AS: } 2 \text { plays } \\
\text { A: } 4 \text { plays }\end{array}$ & $\begin{array}{l}\text { Shorter verse } \\
\text { AS: } 560 \text { lines } \\
\text { A: } 1400 \text { lines }\end{array}$ & $\begin{array}{c}\begin{array}{c}\text { Non-fiction } \\
\text { prose }\end{array} \\
\text { AS: } 1 \text { book } \\
\text { A: } 2 \text { books }\end{array}$ & $\begin{array}{l}\text { Novel and fable } \\
\text { AS: } 1 \text { novel } \\
\text { A: } 2 \text { novels }{ }^{15}\end{array}$ & $\begin{array}{c}\text { Oratory and } \\
\text { letters } \\
\text { AS: } 2 \text { speeches } \\
\text { / } 10 \text { letters } \\
\text { A: } 4 \text { speeches / } \\
20 \text { letters }\end{array}$ \\
\hline Virgil & Lucretius & Plautus & Horace & Sallust & Petronius & Oratory \\
\hline Lucan & Virgil & Terence & Catullus & Caesar & Apuleius & Cicero \\
\hline Statius & Ovid & $\begin{array}{l}\text { Seneca the } \\
\text { Younger }\end{array}$ & Ovid & Livy & Phaedrus & $\begin{array}{l}\text { Pliny the } \\
\text { Younger }\end{array}$ \\
\hline Ovid & & & Propertius & $\begin{array}{l}\text { Valerius } \\
\text { Maximus }\end{array}$ & $\begin{array}{l}\text { Seneca the } \\
\text { Younger }\end{array}$ & Panegyrici Latini \\
\hline Silius Italicus & & & Tibullus & $\begin{array}{l}\text { Velleius } \\
\text { Paterculus }\end{array}$ & & Letters \\
\hline \multirow[t]{3}{*}{ Ennius } & & & Gallus & Tacitus & & Cicero \\
\hline & & & Sulpicia & Suetonius $^{16}$ & & $\begin{array}{l}\text { Pliny the } \\
\text { Younger }\end{array}$ \\
\hline & & & Martial & $\begin{array}{l}\text { Ammianus } \\
\text { Marcellinus }\end{array}$ & & Fronto \\
\hline
\end{tabular}

\footnotetext{
${ }_{14}$ Ancient works are split into "books" which, in turn, are divided into "chapters", this is a standard and unambiguous term within classical scholarship

${ }^{15}$ OR the equivalent in fable material where 30 fables are equivalent to half a novel

${ }_{16} \mathrm{For}$ "Suetonius" one "honk" is taken as heing enuivalent to one "I ife"
}

Figure 1. Types of Latin literature, their stipulated amount per $20 \%$ of the qualification and example authors (not exhaustive)

students' interests. To achieve this, we had to make the content quantifiable in terms that could be regulated by possible non-specialists in a legal framework.

This proved to be an incredibly difficult task, requiring more re-drafts of the subject content than possibly any other issue. Content was 'tagged' as falling into three categories; literature, visual/material culture and (at A Level only) Classical thought. A minimum proportion of each was stipulated for study, with different 'types' of material in each category given weightings based (where possible) on the amount of content found in old specifications. For visual/material culture (GCE Subject Content pages 6-7) we spoke in terms of 'architecture' and 'artefacts and artworks' (to be crass, essentially 'big' things and 'smaller' things), nine types of literature were identified (see Appendix A of the Subject Content one page of which can be seen in Figure 1) and Classical thought (pages 9-10) was quantified by number of thinkers studied in conjunction with one of the six approved areas of thought. This does mean that if one so wished, one can use this document to work out how many vases are worth Plato's ideas about democracy! In addition to these rules there were also mandated minimum amounts of Greek and Roman content. Reimagining the Classical Civilisation specifications made more use of my A Level in Maths than I was expecting.

These minima were integral in shaping the design of the courses; for example, the three groups of components in A Level Classical Civilisation which blend material from different categories. Classics is the ultimate interdisciplinary subject and this use of different material is a good grounding for higher level study, but this structure also kept compulsory options to a minimum. The components in each group contain at least the minimum amount of literature (Group 1), visual/material culture (Group 2) and classical thought (Group 3). This in conjunction with the half-Greek half-Roman compulsory World of the Hero component created a specification with a large degree of flexibility which still met all of the Department for Education's and Ofqual's requirements.

\section{These are our qualifications}

Whilst the subject content documents and Ofqual requirements might be extensive, there is still a good amount of scope for innovation when it comes to specification design. As the changes in the last round of reform were going to be so extensive, we travelled all over the country to lead around 40 Teacher Advisory Groups: events usually hosted by a school attended by teachers from all over the local area. Decisions on the specifications were influenced directly by the feedback we received. We took advice on everything from exam formats (at GCSE teachers told us that exams longer than 90 minutes would be off-putting to students and that integrated Q\&A booklets were essential) to content (inclusion of a compulsory Epic component for GCE Classical Civilisation was received positively almost universally).

We also had a team of specification developers working on individual components and offering their expertise. Most of these were teachers, some of whom also worked as examiners, at various stages of their careers. All of them made an incredibly valuable contribution, especially those who undertook the authoring of the individual components. The time provided by academics was also deeply appreciated; sitting in a very good Italian coffee shop in Cambridge with Professor Tom Harrison thrashing out the finer details of the Invention of the Barbarian and Greek Religion options was a personal highlight.

Creating a specification which is appropriate for secondary school level is a very specific skill, and it is rare to find someone who has never stood in a classroom who can pitch it correctly. Similarly, assessment design is a very technical and precise art form which is so much more complex than I ever appreciated when I was 
in the classroom. These days I have a strange love of Levels of Response grids (with nice, neat, narrow bands for reliable marking) and will explain how grade boundaries work to anyone who will listen. Bringing together the expertise of teachers, academics and assessment specialists is absolutely crucial to create a really strong end result.

This meeting of minds is, however, very difficult to facilitate. Everyone is short of time. No one assumes they are the 'type' of person who gets involved in these endeavours. The timelines to which reforms are completed never feel long enough. As a result, emails go unanswered, job adverts are ignored, and incredibly useful feedback never makes it into the room where decisions are made.

This is where I scare you. Sorry. Reform has not ended. It will happen again and will happen soon. It will not, however, be as wholesale and seismic as the last round. Reform of specifications is also important. It should happen regularly. It 'resets' the exam papers, meaning that content and questions are no longer prohibited due to having been used before, and provides an opportunity for issues to be addressed and improvements made. Well-managed, community-focused reform is good for teachers and students.

So, what will the next reform look like? It will be exam board-led and regulated by Ofqual in accordance with existing regulations. The Department for Education will not change the Subject Content documents any time soon. They will remain legally binding and cannot really be challenged; their consultation and ratification process happened back in 2016-18. We can, however, help the boards to interpret and use these to create qualifications which meet the needs of students and teachers.

The current specifications were the product of a small group of diverse people working incredibly hard together; we had everyone from the NQT+1, to the retired teacher with 40 years of experience; the FE college lecturer to the private school Head of Department; teachers and academics from Cornwall to Scotland. No matter your background or professional status, your contribution might be incredibly valuable. If you see a call for people to offer their views, skills or knowledge, then please do take the time to add your voice and expertise. The Classics community can be a disparate one, with people often working in isolation (when I was a teacher, I did not even know that the Classics Library let alone the Journal of Classics Teaching even existed!) but it is also one of the strongest and most energetic subject communities I have worked with. It would be amazing if people at all levels could help shape the qualifications which are, in turn, helping to shape the next generation of Classicists.

\section{References}

DfE. (2016a, February). Classical civilisation. GCE AS and A level subject content. Retrieved from Department for Education: https://assets.publishing.service. gov.uk/government/uploads/system/uploads/attachment_data/file/593745/ Classical_Civ_A_AS_level_formatted.pdf\#: :text=Subject $\% 20$ content $\% 20$ $4 . \% 20$ Both $\% 20$ AS\%20and\%20A\%20level,the $\% 20$ time $\% 20$ period $\% 20$ $3000 \% 20 \mathrm{BCE} \% 20$ to\%20500\%20CE. Accessed 2 February 2021.

DfE. (2016b, May 6). Consultation outcome. GCSE, AS and A level reform: regulations for ancient history and classical civilisation. Retrieved from Department for Education: https://www.gov.uk/government/consultations/ gcse-as-and-a-level-reform-regulations-for-ancient-history-and-classicalcivilisation. Accessed 2 February 2021.

DfE. (2016c, February 4). Department for Education. Retrieved from GCSE classical civilisation: https://www.gov.uk/government/publications/gcseclassical-civilisation. Accessed 2 February 2021.

DfE. (2016d, February 4). GCE AS and A level ancient history. Retrieved from Department for Education: https://www.gov.uk/government/publications/ gce-as-and-a-level-ancient-history. Accessed 2 February 2021.

DfE. (2016e, February 4). GCE AS and A level classical civilisation. Retrieved from Department for Education: https://www.gov.uk/government/publications/ gce-as-and-a-level-classical-civilisation. Accessed 2 February 2021.

DfE. (2016f, February 4). GCSE ancient history. Retrieved from Department for Education: https://www.gov.uk/government/publications/gcse-ancienthistory. Accessed 2 February 2021.

DfE. (2017a, March 3). GCE AS and A level ancient languages. Retrieved from Department for Education: https://www.gov.uk/government/publications/ gce-as-and-a-level-ancient-languages

DfE. (2017b, March 30). GCE subject-level guidance for ancient languages. Retrieved from Department for Education: https://www.gov.uk/government/ publications/gce-subject-level-guidance-for-ancient-languages. Accessed 2 February 2021.

DfE. (2018, March 9). GCSE ancient languages. Retrieved from Department for Education: https://www.gov.uk/government/publications/gcse-ancientforeign-languages. Accessed 2 February 2021.

DfE. (2020, February 6). Secondary accountability measures (including Progress 8 and Attainment 8). Retrieved from Department for Education: https:// www.gov.uk/government/publications/progress-8-school-performancemeasure. Accessed 2 February 2021.

Gibb, N. (2019, May 16). Schools Minister: The importance of GCSEs. Retrieved from Department for Education. Blog: Education in the media: https:// dfemedia.blog.gov.uk/2019/05/16/schools-minister-the-importance-ofgcses/. Accessed 2 February 2021. 